\title{
LASER SEMIKONDUKTOR GaAs JENIS DOUBLE HETEROJUNCTION SEBAGAI SUMBER CAHAYA DALAM KOMUNIKASI OPTIK
}

\author{
Samy J. Litiloly ${ }^{1)}$, Nicolas Titahelu ${ }^{2)}$ \\ e-mail: ${ }^{1)}$ samyjunus1@yahoo.com, ${ }^{2}$ titahelun@gmail.com \\ Jurusan Teknik Mesin, FT-UNPATTI, Kampus Poka, Ambon 97233. Indonesia
}

\begin{abstract}
ABSTRAK
Telah diteliti suatu sistem junction yang tepat sebagai gelombang carrier dalam komunikasi optik. Mula-mula disampaikan asal muasal munculnya Laser Semikonduktor GaAs, kemudian struktur homojunction, khususnya uraian tentang rapat arus ambang dan daya output saat forward-bias; yang memberikan $\lambda_{\text {output }}$ dengan profil yang tidak tajam (pelebaran $2 \mathrm{~m}$ ) dan daya dibawah $10 \mathrm{~mW}$. Setelah itu, pencampuran III-V terhadap GaAs murni, diciptakan untuk mempertajam profil laser output dan memperbesar dayanya. Struktur yang terbaik untuk keperluan ini adalah double heterojunction $(\mathrm{DH})$ dengan salah satu bahan unggulannya adalah $\mathrm{Ga}_{1-\mathrm{x}} \operatorname{In}_{\mathrm{x}} \mathrm{As}_{1-\mathrm{y}} \mathrm{P}_{\mathrm{y}}$. Kemudian ditunjukkan bahwa bahan ini memberikan $\lambda_{\text {output }} \approx 1,55 \mathrm{~m}$ dan daya output diatas $10 \mathrm{~mW}$ dengan efisiensi operasi $70 \%$.
\end{abstract}

Kata kunci: laser semikonduktor, double heterojunction GaAs, komunikasi optik.

\section{PENDAHULUAN}

Sejak Einstein meletakkan asas-asas emisi stimulasi yang mendasari semua aksi laser, banyak usaha dilakukan oleh para pionir untuk memperoleh medium yang tepat dimana stimulasi dapat berlangsung. Empat puluh tiga tahun kemudian, Maiman (1960) melaporkan laser zat padat "Ruby" $\left(\mathrm{AL}_{2} \mathrm{O}_{3}+\mathrm{Cr}^{3+}\right)$ dengan $\lambda_{\text {output }}=\lambda_{\mathrm{o}} \sim 0,6993 \mathrm{pm}$ (pulsa); sebagai "Real" laser pertama di dunia. Menyusul kemudian dari medium gas $\mathrm{H}_{\mathrm{e}}-\mathrm{N}_{\mathrm{e}}$ dapat dihasilkan laser dengan output daya beberapa miliwatt $(\mathrm{mW})$ pada panjang gelombang $\lambda_{\mathrm{o}} \approx 1,1500$

$\mathrm{m}(\mathrm{CW})$ yang didemonstrasikan oleh Javan dan tim pada tahun 1961.

Riset intensif dalam komunikasi optik pada awal dasawarsa 60-an di Amerika Serikat, membuat orang melirik ke laser untuk dijadikan gelombang carrier yang qualified. Ruby dan $\mathrm{H}_{\mathrm{e}}-\mathrm{N}_{\mathrm{e}}$ tidak memenuhi syarat karena kendala tegangan operasi yang sangat tinggi, daya yang rendah, $\lambda_{o}$ yang tidak menguntungkan, juga cost yang terlalu mahal. Untuk mengatasi hal ini Benhard dan Duraffog, juga Basov dan tim, secara terpisah mengusulkan medium stimulasi lain, dimana dapat dihasilkan laser yang menjanjikan. Medium yang diusulkan disini adalah junction antara semikonduktor type $\mathrm{p}$ dengan semikonduktor type $\mathrm{n}$ yang sedang forward-bias. Kemajuan yang luar biasa terjadi, pada tahun 1962 lahirlah laser generasi ketiga yaitu laser semikonduktor, yang pada waktu itu memakai bahan GaAs (Galium Arsenit) sebagai bahan pertama yang bisa menghasilkan laser dengan $\lambda_{\mathrm{o}} \approx 1,1 \mathrm{~m} \mathrm{~s} / \mathrm{d} 1,6$ $\mathrm{m}$ dan daya yang bisa mencapai puluhan $\mathrm{mW}$.

Pada bagian selanjutnya, setelah ini, disampaikan kajian teoritis dan metoda. Dimulai dengan bentuk standar laser semikonduktor GaAs yang junctionnya homogen (homojunction) beserta pola penguatannya (gain) terhadap gelombang yang masuk. Juga syarat populasi inversi supaya laser homojunction dapat beraksi, serta prospek menuju junction yang tidak homogen; atau junction yang berasal dari GaAs yang sudah dicampuri dengan bahan-bahan lain seperti Al, P, In, Sb, sesuai pola pencampuran III-V, guna memperoleh gain yang lebih tajam. Juga diuraikan rapat arus ambang yang harus diterapkan pada sistem homojunction agar forward-bias bisa menghasilkan foton-foton terstimulasi ketika rekombinasi. Juga diajukan suatu hipotesa yang menyatakan bahwa sistem homojunction GaAs dapat menghasilkan gain yang lebih tinggi dan lebih monokromatis; bila sistem dibuat heterojunction. Termasuk juga ulasan tentang cara penelitian yang pada akhirnya membuktikan hipotesa yang ada. Bagian selanjutnya berisikan hasil-hasil riset yang telah dilakukan terhadap struktur heterojunction kombinasi III-V terhadap homojunction GaAs; termasuk disini daya output dan $\lambda_{\text {output }}$ yang dihasilkannya serta pemakaiannya dalam komunikasi optik. Pada bagian terakhir diberikan kesimpulan.

\section{KAJIAN TEORI DAN METODA}

Bentuk fisik material laser semikonduktor homojunction adalah seperti terlihat pada Gambar 1 sbb.: (Wilson J., and Hawkes J. F. B. 1998) 


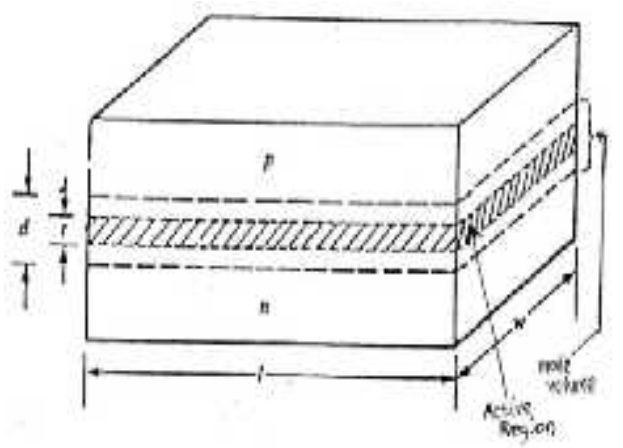

Gambar 1. Situasi fisik homojunction p-n

Disini; $1=$ panjang fisik bahan, $\mathrm{w}=$ lebar, $\mathrm{t}=$ tebal daerah dimana stimulasi terjadi (daerah aktif), $\mathrm{d}=$ tebal tambahan dari $\mathrm{t}$ dimana stimulasi masih mungkin terjadi. Baik $\mathrm{t}$ maupun $\mathrm{d}$, masih berada dalam daerah junction. Keadaan pita energi dari sistem homojunction bila bahan $\mathrm{n}$ didoping sangat banyak adalah:
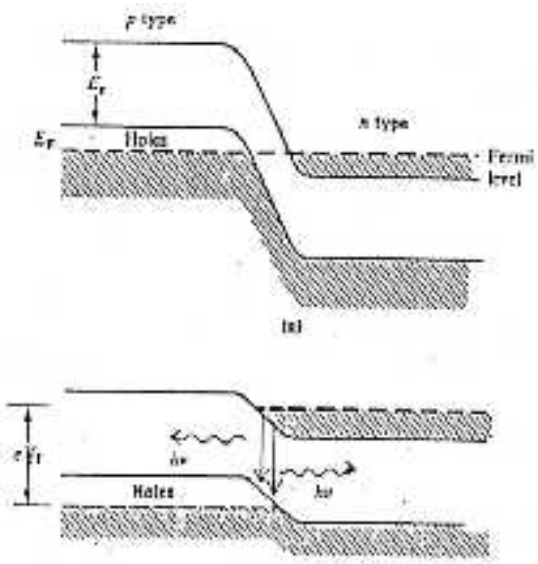

$\Leftrightarrow$

Gambar 2. Doping sangat banyak pada p-n Junction : a). Kesetimbangan; b. Forward-bias

Bila tegangan forward-bias mendekati nilai $\mathrm{E}_{\mathrm{g}} / \mathrm{e}$, maka elektron-elektron dan hole-hole akan diinjeksikan dalam jumlah yang cukup untuk menciptakan populasi inversi di daerah aktif, sbb.:
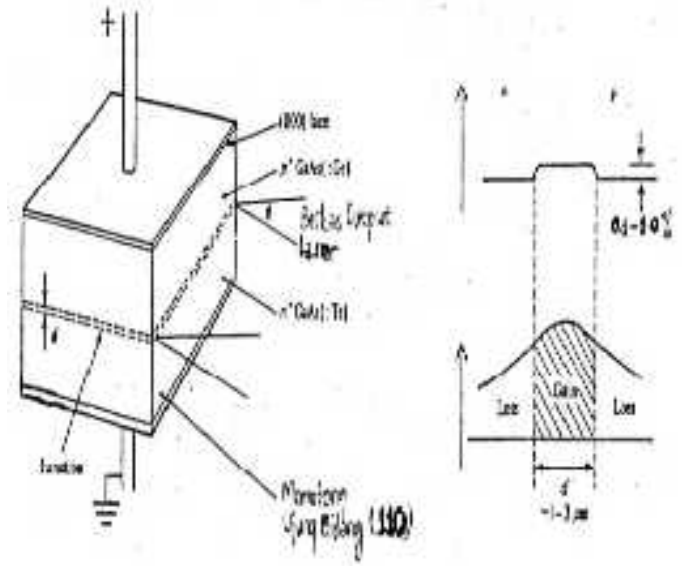

Gambar 3. Forward-bias homojunction GaAs
Disini, emisi foton terkurung di daerah $\mathrm{t}$ dan $\mathrm{d}$ pada junction dimana besarnya divergensi laser sangat ditentukan oleh perbedaan $\mathrm{t}$ dan d. Gambar 3 menunjukkan sangat kecilnya perubahan indeks bias pada daerah junction juga pola penguatan yang tidak terlalu baik pada daerah aktifnya. Pada sistem ini, syarat ambang yang harus dipenuhi untuk populasi inversi adalah populasi ambang hole dalam pita valensi, yaitu:

$$
\left(\mathrm{N}_{2}\right)_{\mathrm{th}}=\mathrm{d} / \mathrm{t}\left[\frac{8 \pi v_{\mathrm{o}}^{2} \mathrm{~K}_{\mathrm{th}} \tau_{21} \quad v \mathrm{n}^{2}}{\mathrm{c}^{2}}\right]
$$

Disini, $v_{\mathrm{o}}$ dan $\quad v$ diperoleh dari kurva emisi transisi sbb:

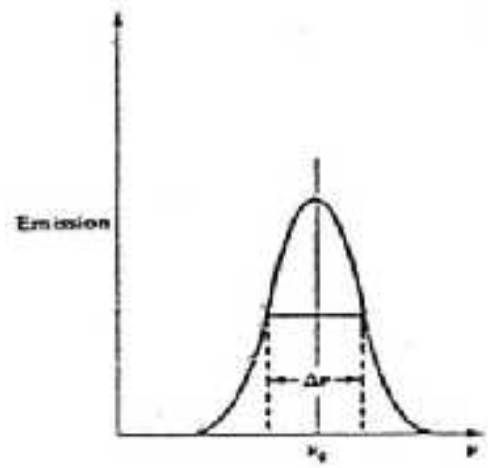

\section{Gambar 4. Kurva emisi dari $\mathrm{N}_{2}$ ke $\mathrm{N}_{1}$}

$\mathrm{K}_{\mathrm{th}}=$ Penguatan ambang, $\tau_{21}=$ Lifetime dari $\mathrm{N}_{2}$, dan $\mathrm{n}$ adalah indeks bias bahan GaAs. Yang penting untuk diperhatikan adalah faktor $\mathrm{d} / \mathrm{t}$ yang ditentukan langsung oleh keadaan fisik semikonduktor (lihat Gambar 1), dengan hasil terbaik adalah $\mathrm{d} / \mathrm{t}=1$. Jadi, dengan mengatur besaran-besaran diatas dan dengan memperhatikan pengaruhnya terhadap $v$ pada Gambar 4, maka dapat dibuat suatu bahan dari campuran GaAs dengan unsur-unsur segolongannya yaitu III dan V, agar $v$ yang terjadi sekecil mungkin (se-monokromatis mungkin), sesuatu yang sangat diperlukan pada komunikasi optik. Setelah populasi inversi tercapai menurut (1) maka emisi stimulasi akan terjadi. Untuk itu, perlu adanya suplai arus yang kontinyu dan mencapai harga ambang tertentu.

\section{Rapat Arus Ambang Sistem Homojunction}

Berangkat dari (1); jika rapat arus yang mengalir melalui sistem adalah $\mathrm{J}\left(\mathrm{Am}^{-2}\right)$, maka jumlah elektron tiap detik yang masuk ke volume $1 \times \mathrm{t} \times \mathrm{w}$ adalah $\mathrm{J} / \mathrm{e}$. Rapat elektronnya adalah J/et $\mathrm{m}^{-3} \mathrm{~s}^{-1}$. Dalam kesetimbangan, jumlah rapat elektron pada pita konduksi; harus dapat mensuplai suatu kecepatan rekombinasi yang mesti sama dengan kecepatan injeksi $\mathrm{N}_{2} / \tau_{\mathrm{e}}$ dimana $\tau_{\mathrm{e}}$ adalah lifetime elektron yang bisa saja tidak sama dengan $\tau_{12}$. Jadi, rapat elektron tiap detik adalah: 


$$
\frac{(\mathrm{J})_{\mathrm{th}}}{\text { et }}=\frac{\left(\mathrm{N}_{2}\right)_{\mathrm{th}}}{\tau_{\mathrm{e}}}
$$

dan substitusi (1) menghasilkan:

$$
(\mathrm{J})_{\mathrm{th}}=\frac{\text { ed }}{\tau_{\mathrm{e}}} \frac{\left(8 \pi v_{\mathrm{o}}^{2} \mathrm{~K}_{\mathrm{th}} \tau_{21} \quad v \mathrm{n}^{2}\right)}{\mathrm{e}^{2}}
$$

Substitusikan bentuk eksplisit $\mathrm{K}_{\mathrm{th}}$; maka

$$
(J)_{\text {th }}=\frac{8 \pi v_{\mathrm{o}}^{2} \mathrm{e} \mathrm{d} \mathrm{K}_{\mathrm{th}} \tau_{21} v \mathrm{n}^{2}}{\tau_{\mathrm{e}} \mathrm{c}^{2}}\left[\gamma+1 / 21 \ln \left(1 / \mathrm{R}_{1} \mathrm{R}_{2}\right)\right]
$$

Disini $\gamma \equiv$ koefisien kehilangan efektif, dimana $\tau_{d} / \tau_{21}$ pada persamaan sering ditulis sebagai $\eta_{\mathrm{i}} \equiv$ Efisiensi Kuantum Internal; yang secara fisis menyatakan seberapa besar elektron-elektron (atau hole-hole) di $\mathrm{N}_{2}$, terlibat rekombinasi radiatif.

\section{Daya Output}

Daya keluaran yang bisa dicapai sistem adalah:

$$
\mathrm{P}=\mathrm{A}\left[\mathrm{J}-\mathrm{J}_{(\mathrm{th})}\right] \frac{\eta_{\mathrm{i}} \mathrm{h} v}{\mathrm{e}}
$$

dimana A adalah luasan junction. Efisiensi kuantum eksternal selanjutnya didefinisikan sebagai perbandingan dari kecepatan output foton yang dicapai terhadap kecepatan injeksi (muatan-muatan tiap detik) yaitu:

$$
\eta_{\mathrm{ex}}=\frac{\mathrm{d}\left[\mathrm{P}_{\mathrm{o}} / \mathrm{h} v\right]}{\mathrm{d}\left[\mathrm{A} / \mathrm{e}\left|\mathrm{J}-(\mathrm{J})_{\mathrm{th}}\right|\right]}
$$

dimana $\mathrm{P}_{\mathrm{o}}$ diperoleh lewat (5) dikalikan ( $\left.\mathrm{K}_{\mathrm{th}} \operatorname{tanpa} \gamma\right)$ dibagi $\left(\mathrm{K}_{\text {th }}\right.$ dengan $\left.\gamma\right)$ yaitu:

$$
\mathrm{P}_{\mathrm{o}}=\mathrm{P} \frac{\mathrm{K}_{\text {th }} \text { tanpa } \gamma}{\mathrm{K}_{\text {th }} \text { dengan } \gamma}
$$

Output daya yang dicari; dimana bentuk eksplisitnya adalah:

$$
\mathrm{P}_{\mathrm{o}}=\frac{\mathrm{A}\left[\mathrm{J}-(\mathrm{J})_{\mathrm{th}} \eta_{\mathrm{i}} \mathrm{h} v\right.}{\mathrm{e}} \frac{\left[1 / 21 \ln \left(1 / \mathrm{R}_{1} \mathrm{R}_{2}\right)\right]}{\left[\gamma+1 / 21 \ln \left(1 / \mathrm{R}_{1} \mathrm{R}_{2}\right)\right]}
$$

dengan asumsi $R_{1}=R_{2}$, maka (6) menjadi

$$
\eta_{\mathrm{ex}}=\eta_{\mathrm{i}}\left(\frac{\ln \left(1 / \mathrm{R}_{1}\right)}{1+\ln \left(1 / \mathrm{R}_{1}\right)}\right)
$$

Dari sini, dengan cara eksperimen kita bisa menghitung efisiensi kuantum internal dengan memanfaatkan beragam nilai $\eta_{\text {ex }}$ dan 1 yang sudah diketahui sebelumnya, karena $\gamma$ dan $\mathrm{R}_{1}$ bisa dibuat tetap (konstanta). Khusus untuk GaAs, telah dihitung

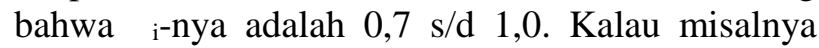
sekarang tegangan forward-bias adalah $\mathrm{V}_{\mathrm{f}}$, kemudian daya masukan adalah $\mathrm{V}_{\mathrm{f}} \mathrm{AJ}$; maka efisiensi laser GaAs dalam input elektrik ke output laser adalah :

$$
\eta=\frac{\mathrm{P}_{\mathrm{o}}}{\mathrm{V}_{\mathrm{f}} \mathrm{AJ}}=\eta_{\mathrm{i}}\left(\frac{\mathrm{J}-(\mathrm{J})_{\mathrm{th}}}{\mathrm{J}}\right)\left(\frac{\mathrm{h} v}{\mathrm{eV}_{\mathrm{f}}}\right) \frac{\ln \left(1 / \mathrm{R}_{1}\right)}{\gamma 1+\ln \left(1 / \mathrm{R}_{1}\right)}
$$

Dari Gambar 2 terlihat $\mathrm{eV}_{\mathrm{f}}=\mathrm{h} v$; sehingga untuk $\mathrm{J}>>$ $(\mathrm{J})_{\text {th }}$ dimana $[1 / 1]\left[1 / \mathrm{R}_{1}\right] \gg \gamma$, maka $\eta$ dapat didekati oleh $\eta_{\text {i. }}$ Khusus untuk laser semikonduktor GaAs; maka $\eta_{\mathrm{i}}$-nya yang diatas 0,7 adalah tergolong besar, sehingga ia dikatakan mempunyai efisiensi daya yang sangat tinggi. Pada (4), terlihat bahwa untuk $(\mathrm{J})_{\text {th }}$ yang besar akan memerlukan d yang besar juga. Padahal d sangat berpengaruh pada konvergensi berkas laser yang dihasilkan; berarti juga monokromasitas (Gambar 3). Biasanya ( $\mathrm{J})_{\text {th }}$ yang diizinkan itu $\approx 10$ $\mathrm{mm}^{-2}$ pada temperatur kamar, untuk homojunction GaAs yang memberikan $\mathrm{d} \approx 2 \mathrm{~m}$; suatu penyebab munculnya dispersi/losses yang potensial dalam komunikasi optik bila GaAs mau dipakai sebagai laser semikonduktor untuk sumber carrier waves. Masalah lain adalah $\gamma$ pada penyebut (8) yang bila menjadi besar sedikit saja, akan mengecilkan daya output, padahal untuk GaAs; $\gamma=10^{3} \mathrm{~m}^{-1}$. Penyebab d dan $\gamma$ yang merepotkan ini terletak pada indeks bias bahan GaAs murni yang didalamnya emisi stimulasi mengalami gain. Profil gain dan variasi indeks bias dimaksud, sudah diberikan pada Gambar 3; sedangkan $\gamma$ sebagai loss coefficient, bergantung semata-mata pada sifat alami GaAs. Untuk mengatasi masalah ini, perlu diciptakan sumber laser berbahan dasar semikonduktor GaAs tersebut yang dapat menghasilkan gain besar dengan profil yang tajam dan dengan output daya diatas $10 \mathrm{~mW}$. Dalam makalah ini penulis mengangkat hal tersebut sebagai hipotesa; sesuatu yang akan menuntun kita kepada struktur baru yang saat ini dikenal sebagai laser heterojunction. Parameter d dan $\gamma$; didalam rekayasa untuk membuktikan hipotesa diatas, penulis melakukan penelusuran literatur dan pembuktian eksperimen terhadapnya; terutama penulis meninjau 
bagaimana konsep heterojunction itu diwujudkan dalam bentuk struktur nyata, serta berkas laser yang diperoleh lewat struktur tersebut.

\section{HASIL DAN PEMBAHASAN}

Laser heterojunction dari bahan GaAs dan campuran-nya adalah merupakan golongan III untuk mengganti beberapa bagian dari As. Fraksi dari penambahan tersebut diatur sedemikian rupa sehingga bersama-sama dengan GaAs murni, bisa diperoleh suatu struktur yang variasi indeks bias dan energi-gap-nya adalah tajam. Juga disini $(J)_{\text {th }}$ diusahakan serendah mungkin, supaya d-nya sekecil mungkin; atau stimulasi betul-betul dapat dipusatkan di active region (lihat Gambar 1).

\section{Struktur Heterojunction GaAs}

Disini dikenal dua macam struktur, yaitu single heterojunction $(\mathrm{SH})$ dan double heterojunction (DH). Sesuai dengan namanya maka SH hanya akan mempertajam profil gain pada suatu bagian, sedangkan DH pada kedua bagiannya. Ilustrasi untuk kedua macam struktur tersebut, ada dalam Gambar 5 dibawah ini.

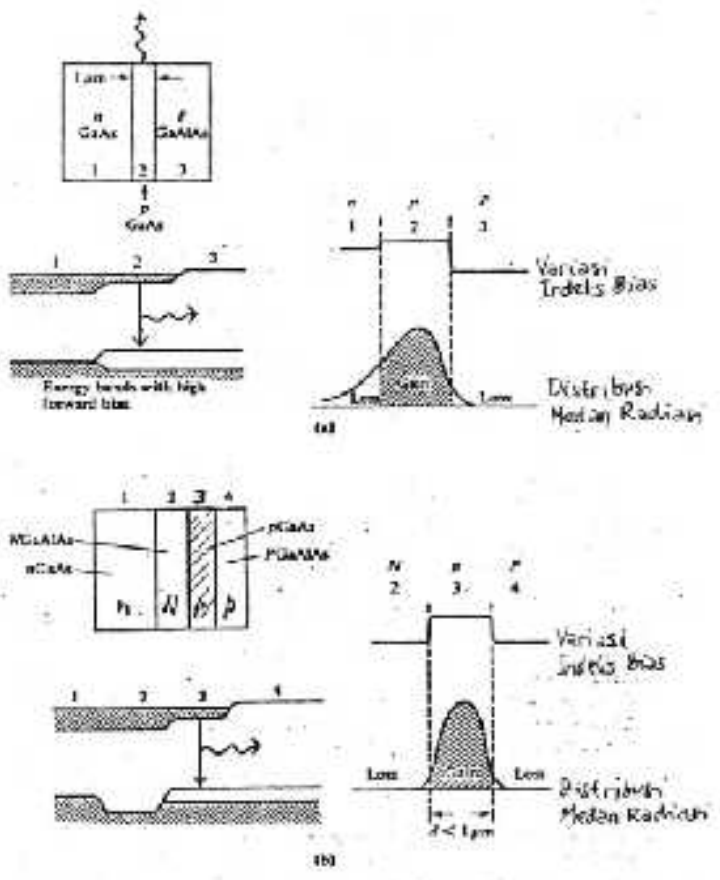

Gambar 5. Forward-bias heterojunction: a). SH, dan b). DH

Terlihat bahwa masalah dispersi maupun loss pada $i$ (Gambar 3) segera terselesaikan dengan kehadiran $\mathrm{d}<1$ m. Untuk SH, maka lapisan GaAs type $\mathrm{P}$ diletakan sebagai lapisan antara (Sanwich) yang diapit oleh bahan yang berindeks bias lebih rendah $\mathrm{Ga}_{1-\mathrm{x}} \mathrm{A} 1_{\mathrm{x}}$ As type $\mathrm{P}$ pada satu sisi, dan GaAs type $\mathrm{n}$ pada sisi yang lain. Disini $\mathrm{x}$ menyatakan seberapa bagian/fraksi Ga yang diambil oleh Al. Pada $\mathrm{DH}$, selain $\mathrm{Ga}_{1-\mathrm{x}} \mathrm{A} 1_{\mathrm{x}} \mathrm{As}$ type $\mathrm{P}$, type $\mathrm{N}$-nya pun diletakkan juga pada sisi yang lain dari sistem yaitu diantara GaAs type N-P-P (SH) dan N-N-P (DH) ; dimana sisi active region berada di GaAs type P. Disamping itu, lewat struktur DH seperti ini maka $(J)_{\text {th }}$ dapat dibuat seoptimal mungkin untuk menghindari pembesaran d. Struktur lanjutan untuk ini, disebut sebagai "Stripe Geometry" yang skemanya bisa dilihat pada Gambar 6. Pada type P di GaAs dimana active region-nya berada.

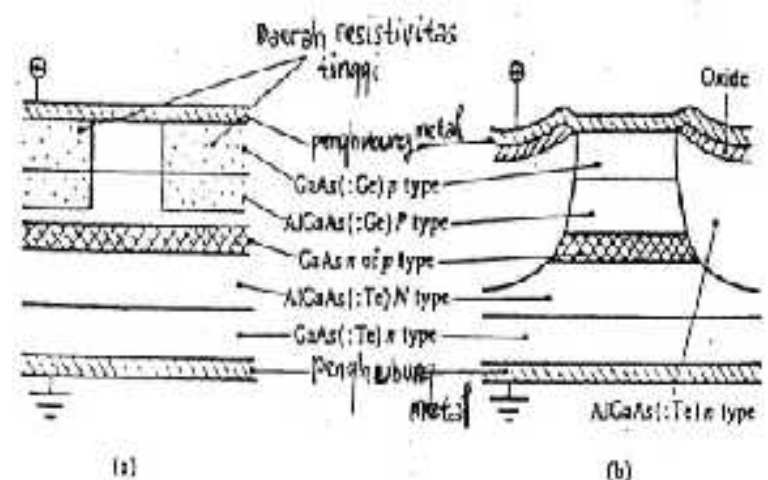

Gambar 6. DH Stripe geometry

Namun dengan stripe geometry, output daya sering mengalami gangguan yang disebut "Kink" pada panjang stripe tertentu; misalnya pada drive current $\sim 100 \mathrm{~mA}$ dengan 20 m stripe. Keadaan "Kink" ini dapat dilihat pada Gambar 7 sbb.:
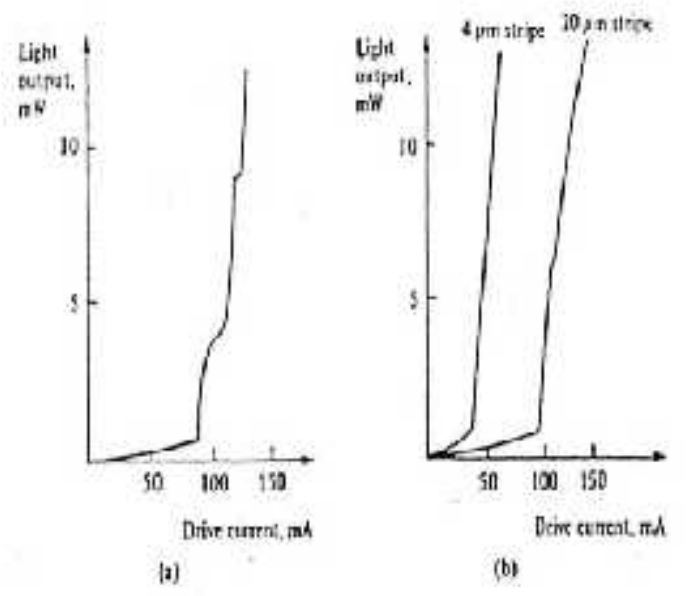

Gambar 7. "Kink" pada DH stripe Geometry: a). Secara umum, dan b). Pada 4 m dan $20 \mathrm{~m}$

"Kink" ini berkaitan dengan losses atau dispersi berapa pun kecilnya yang muncul diluar active region pada daerah (d-t) yang memang cukup kecil (Gambar 1) dan memang terjadi pada $J>(J)_{\text {th. }}$. Disini terjadi interaksi antara sifat-sifat optik bahan, dengan ditribusi foton emisi stimulasi diluar active region. Dengan membuat stripe yang cukup panjang (diatas 20 m) maka ketidakstabilan "Kink" tersebut dapat diperkecil; seperti yang ditunjukan pada gambar $7 \mathrm{~b}$. 


\section{Daya Output dan $\lambda_{\text {output }}$ DH GaAlAs}

Untuk pencampuran $\mathrm{Al}$ terhadap GaAs yang menghasilkan GaAlAs, maka Daya Output juga bergantung kepada temperatur. Bagaimana bentuk ketergantungan tersebut? dapat dilihat dalam Gambar 8 berikut ini:

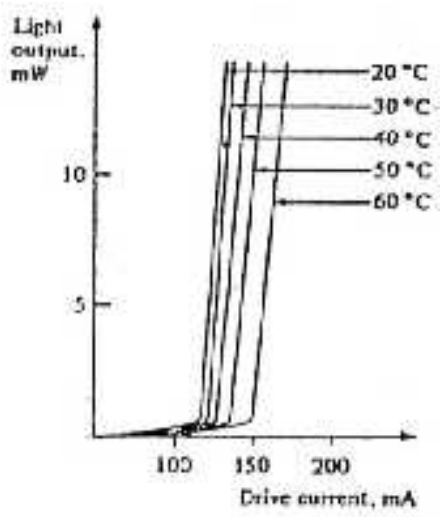

Gambar 8. Daya output DH GaA As 20 m stripe pada temperatur tertentu.

Sedangkan produk daya ini mempunyai $\lambda_{\text {output }}$ yang khas yang berhubungan langsung dengan Energy Gap dari latis-latis yang dibentuk melalui pola III-V, terhadap GaAs murni. Disini, konstanta latis juga turut menentukan $\lambda_{\text {output }}$ karena foton-foton stimulasi bisa mengalami difraksi disana. Hubungan antara pola campuran III-V dengan konstanta latis terhadap Energy Gap dan $\lambda_{\text {output }} \mathrm{DH}$; dapat dilihat pada gambar berikut ini:

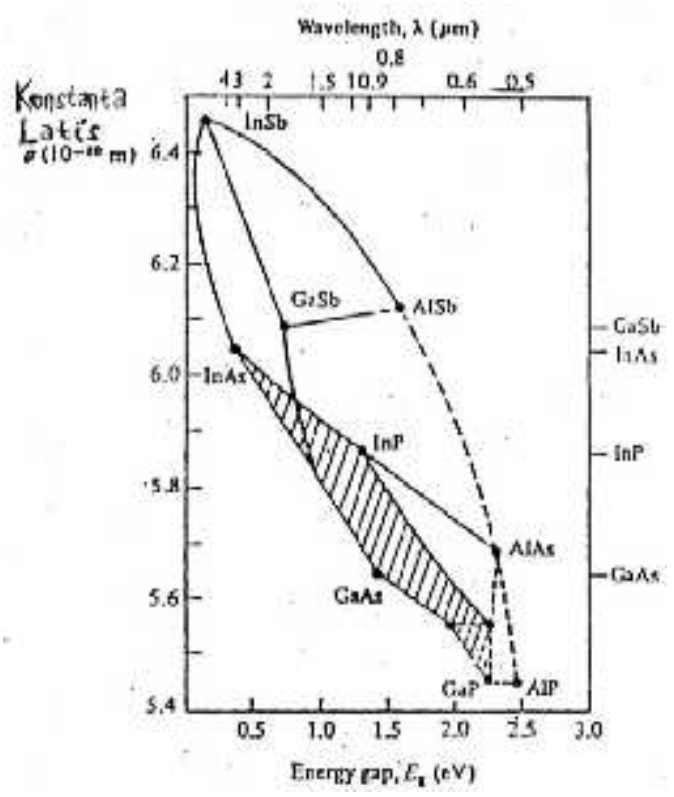

Gambar 9. $\lambda_{\text {output }}$ (Energy Gap) versus konstanta latis; pencampuran III-V.

Disini garis putus-putus menghubungkan indirect band-gap, daerah arsiran menunjukan daerah campuran $\mathrm{Ga}_{\mathrm{x}} \mathrm{In}_{1-\mathrm{x}} \mathrm{p}_{\mathrm{y}} \mathrm{A}_{\mathrm{s} 1-\mathrm{y}}$; dengan $\mathrm{x}$ dan $\mathrm{y}$ dapat berasal dari GaAs dan InP.

\section{Implementasi dalam Komunikasi Optik}

Pada bagain awal sudah diungkapkan bahwa riset dalam komunikasi optik-lah yang mendorong kelahiran laser semikonduktor GaAs. Saat itu sedang dicari gelombang pembawa yang memberikan attenuasi minimal $(1,1 \mathrm{~m}<\lambda<1,6 \mathrm{~m})$, dan ternyata dengan pencampuran III-V terhadap GaAs, hal itu bisa dipenuhi. Grafik transmission loss dari single mode fiber silikon dalam komunikasi optik adalah:

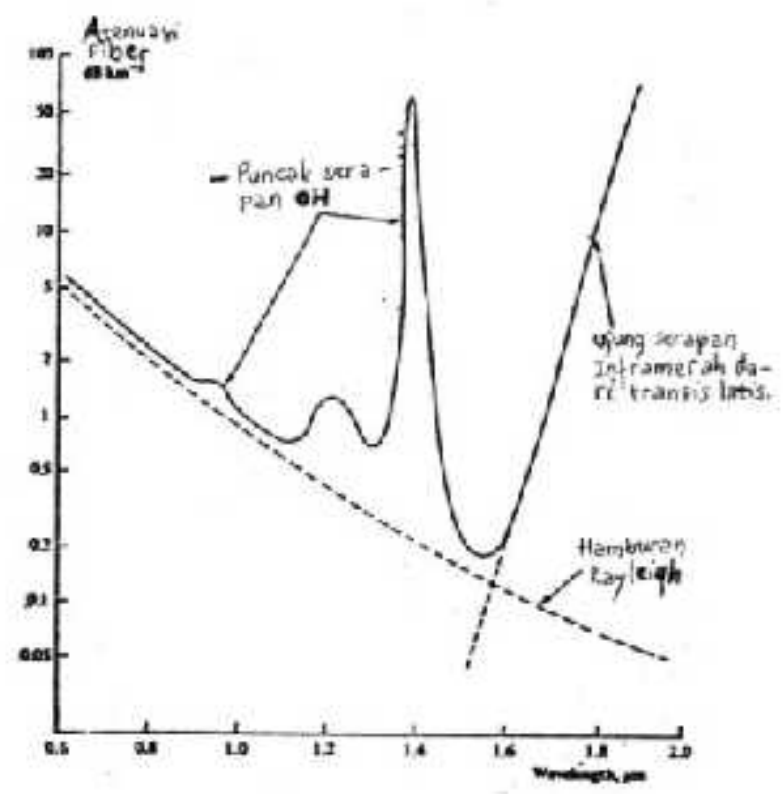

Gambar 10. Attenuasi versus $\lambda$ (single mode) untuk fiber silikon.

Disini $\lambda$ yang memberikan loss minimal $(\sim 0,15 \mathrm{db}$ $\mathrm{km}^{-1}$ ) adalah $\lambda \approx 1,55 \mathrm{~m}$ betul-betul dapat dipenuhi oleh DH Laser Campuran $\mathrm{Ga}_{1-\mathrm{x}} \mathrm{In}_{\mathrm{x}} \mathrm{As}_{1-\mathrm{y}} \mathrm{P}_{\mathrm{y}}$. Bahan semacam ini terdapat didaerah arsiran pada Gambar 11 berikut ini: 


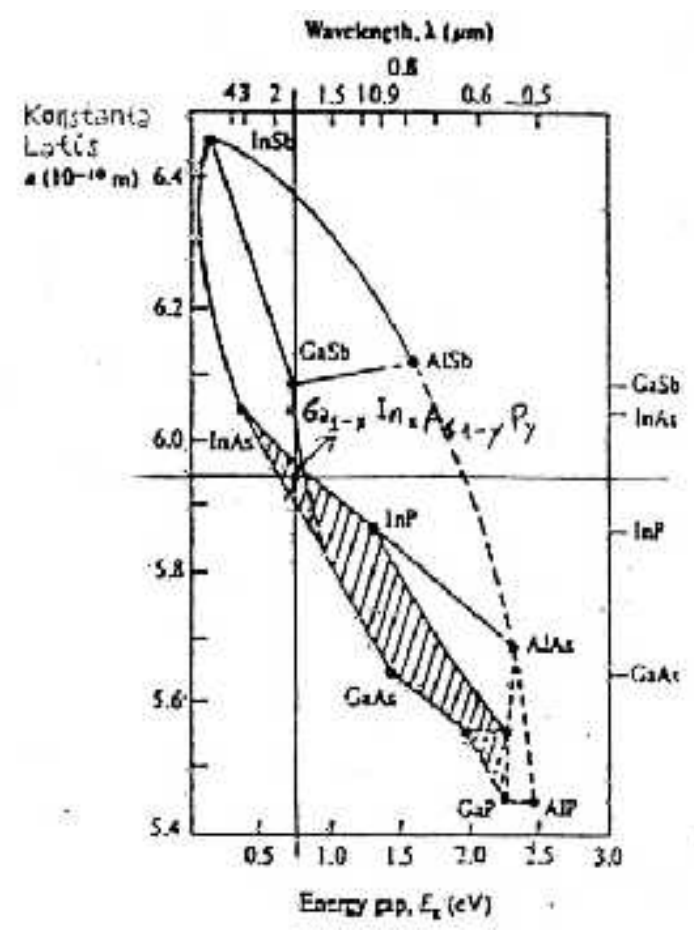

\section{Gambar 11. Ga $_{1-\mathrm{x}} \operatorname{In}_{\mathrm{x}} \mathbf{A s}_{1-\mathrm{y}} \mathbf{P}_{\mathrm{y}}$ pada diagram $\lambda$ versus campuran III-V}

Dalam hal ini, struktur $\mathrm{Ga}_{1-\mathrm{x}} \mathrm{In}_{\mathrm{x}} \mathrm{As}_{1-\mathrm{y}} \mathrm{P}_{\mathrm{y}}$ untuk keperluan tersebut adalah sebagai berikut:
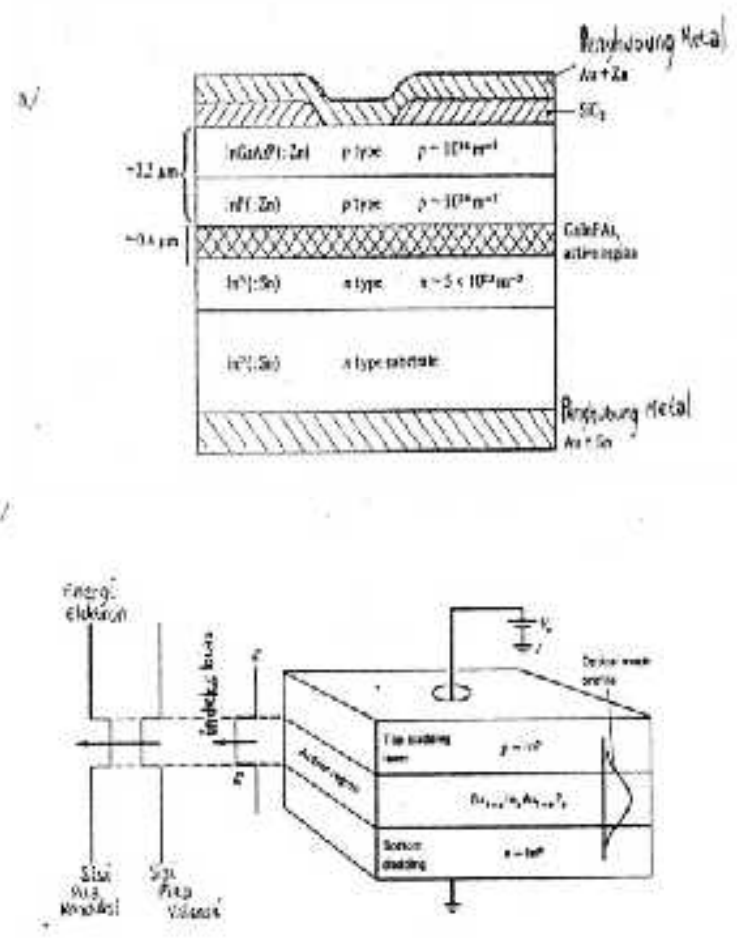

Gambar 12. DH Ga1-x $\operatorname{In}_{\mathrm{x}} \mathrm{As} \mathbf{1}_{1-\mathrm{y}} \mathrm{P}_{\mathrm{y}}$ laser: a). Struktur, dan b). Forward-bias
Disini, struktur forward-bias-nya akan memberikan output daya diatas $10 \mathrm{~mW}$, sesuai Gambar 8 dengan $\lambda_{\text {output }} \approx 1,55 \mathrm{~m}$.

\section{KESIMPULAN}

\section{Umum:}

Laser semikonduktor sebagai laser generasi ketiga, mempunyai keunggulan komparatif terhadap laser "Ruby" dan laser "He-Ne"; karena bisa digunakan dalam komunikasi optik. Tegangan operasi yang rendah (daerah $1,1 \mathrm{~m}<\lambda_{\text {output }}<1,6$ $\mathrm{m}$ ), output daya yang dibawah $10 \mathrm{~mW}$, dan pelebaran profil gain $2 \mu \mathrm{m}$; membuat homojunction terus diperbaiki hingga menjadi heterojunction; semuanya dengan pola campuran III-V terhadap GaAs. Sedangkan efisiensi laser yang diperoleh yaitu $\sim 70 \%$ adalah sangat tinggi

\section{Khusus:}

Sumber laser $\mathrm{Ga}_{1-\mathrm{x}} \mathrm{In}_{\mathrm{x}} \mathrm{As}_{1-\mathrm{y}} \mathrm{P}_{\mathrm{y}}$ double heterojunction (DH) stripe geometry telah memberikan solusi terbaik untuk memperoleh gelombang carrier yang qualified dalam sistim komunikasi optik jarak jauh dengan fiber silikon. Yaitu karena $\lambda_{\text {output-nya }} 1,55 \mu \mathrm{m}$, output daya-nya diatas $10 \mathrm{~mW}$, pelebaran profil gain-nya kurang dari $2 \mu \mathrm{m}$, serta efisiensi operasi laser-nya yang tinggi yaitu sekitar $70 \%$; adalah sangat prospektif untuk waktu sekarang dan dimasa depan.

\section{DAFTAR PUSTAKA}

Laud, B. B. 1988. Laser dan Optik Non-Linier, (Penerjemah: Susanto). UI-Press. Jakarta.

Leinwoll, S. 1965. Understanding Lasers and Masers, 37-42. John F. Rider Publ. Inc. New York.

Steele, E. L. 1968. Optical Lasers in Electronics, 224-255. John Wiley and Sons. New York.

Suematsu, Y. and Iga, K-I. 1982. Introduction to Optical Fiber Communications. John Wiley and Sons. New York.

Wilson, J. and Hawkes, J. F. B. 1998. Optoelectronics An Introduction, Prentice Hall International. New Jersey.

Yariv, A. 1989. Quantum Electronics, Third Edition, 243-253. John Wiley and Sons. New York. 